Review Article

\title{
Familial Dysautonomia: Mechanisms and Models
}

\author{
Paula Dietrich ${ }^{1}$ and Ioannis Dragatsis ${ }^{1}$ \\ ${ }^{1}$ Department of Physiology, The University of Tennessee, Memphis, TN, USA
}

\begin{abstract}
Hereditary Sensory and Autonomic Neuropathies (HSANs) compose a heterogeneous group of genetic disorders characterized by sensory and autonomic dysfunctions. Familial Dysautonomia (FD), also known as HSAN III, is an autosomal recessive disorder that affects $1 / 3,600$ live births in the Ashkenazi Jewish population. The major features of the disease are already present at birth and are attributed to abnormal development and progressive degeneration of the sensory and autonomic nervous systems. Despite clinical interventions, the disease is inevitably fatal. FD is caused by a point mutation in intron 20 of the IKBKAP gene that results in severe reduction in expression of IKAP, its encoded protein. In vitro and in vivo studies have shown that IKAP is involved in multiple intracellular processes, and suggest that failed target innervation and/or impaired neurotrophic retrograde transport are the primary causes of neuronal cell death in FD. However, FD is far more complex, and appears to affect several other organs and systems in addition to the peripheral nervous system. With the recent generation of mouse models that recapitulate the molecular and pathological features of the disease, it is now possible to further investigate the mechanisms underlying different aspects of the disorder, and to test novel therapeutic strategies.
\end{abstract}

Keywords: Familial Dysautonomia, HSAN, IKAP, Ikbkap, ELP1.

Received: December 30, 2015; Accepted: March 16, 2016.

\section{Introduction}

Hereditary Sensory and Autonomic Neuropathies (HSANs) compose a heterogeneous group of rare peripheral neuropathies characterized by loss of temperature and pain perception, in combination with other sensory and autonomic abnormalities. HSANs are classified clinically into five major types based on age of onset, mode of inheritance, and major clinical features (Dyck, 1993). Up to now, HSAN disease-causing mutations have been identified in over 10 genes. For instance, HSAN type IV, also known as Congenital Insensitivity to Pain with Anhidrosis (CIPA), is caused by mutations in the nerve growth factor (NGF) receptor (TrkA/NTRK1), and HSAN type V is caused by mutations in NGF that either prevent its processing, secretion, or downstream signaling (Rotthier et al., 2012; Capsoni, 2014; Indo, 2014).

Familial Dysautonomia (FD, MIM 223900), also known as "Riley-Day syndrome", or HSAN type III, is the most prevalent HSAN. FD is an autosomal recessive congenital sensory and autonomic neuropathy that affects almost exclusively individuals of Ashkenazi, or Eastern European, Jewish extraction, although non-Jewish cases have also been reported (Guzzetta et al., 1986; Leyne et al.,

Send correspondence to Paula Dietrich. Department of Physiology, The University of Tennessee, Health Science Center, 71 South Manassas Street, Translational Research Building, rm 325, Memphis, TN 38163, USA. Email: pdietric@uthsc.edu
2003; Silveira et al., 2012; MIM 223900). FD was first described in 1949 (Riley et al., 1949), based on reports of five children, all Jewish, who presented with diminished production of tears, excessive sweating and salivation, red blotching of the skin, reduced deep tendon reflexes, and marked arterial hypertension. Furthermore, two of the children did not complain when their feet were immersed in ice-cold water, suggesting impaired temperature perception. Over the following decade, additional cases with marked similarities were described, all of them of children with Jewish parents, suggesting that the disease was genetically inherited. The findings in the first few FD patients initially pointed to a central disturbance of autonomic function. Further investigations led to the recognition that several of the FD features, such as reduced pain and temperature perception, and cardiovascular abnormalities were caused by peripheral autonomic and sensory deficits. Despite marked similarities with other HSANs, FD has unique features that distinguish it from the other hereditary neuropathies. The clinical diagnosis of FD is based on the presence of the following cardinal features: absence of fungiform papillae on the tongue, absence of axon flare after intradermal histamine injection, decreased or absent deep tendon reflexes, absence of overflow emotional tears, and Ashkenazi Jewish descent (Axelrod and Pearson, 1984). Several symptoms of the disease are already present at birth, and worsen over time, suggesting that FD is a congenital progressive disorder. Initially, FD patients did not 
survive past childhood, but today with early intervention and supportive treatment the mean age of the FD population is approximately 15 years of age, with a $50 \%$ chance of surviving up to 40 years of age (Axelrod et al., 2002; Gold-von Simson and Axelrod, 2006). Still, current treatments for FD are highly invasive, far from optimal, and there is no cure for this devastating disease. The most common causes of death are acute aspiration, chronic pneumonia and sudden death during sleep (Axelrod et al., 2002). With the identification of the genetic mutation that causes FD, the last decade has been one of great advances in terms of understanding the mechanisms underlying FD, and also for unraveling the essential roles of its mutated gene, $I K B K A P$, and its encoded protein, IKAP, in multiple biological processes.

\section{Genetics and epidemiology}

FD affects 1:3,600 Ashkenazi Jewish live births, with United States and Israel each having about $33 \%$ of the existing total population (Gold-von Simson and Axelrod, 2006). Carrier frequency ranges from $1 / 27$ to $1 / 32$ in the general Ashkenazi Jewish population, with individuals from Polish descent having a higher carrier frequency of 1/18 (Blumenfeld et al., 1999; Dong et al., 2002; Lehavi et al., 2003). While it became clear early on that FD was a hereditary recessive disorder, the genetic basis of FD was only identified in 2001. By studying 26 families with multiple affected members, the FD gene (originally called "DYS"), was mapped to chromosome 9q31. Haplotype analyses of $441 \mathrm{FD}$ chromosomes revealed the presence of a major haplotype observed in $435(98.6 \%)$ of the cases (Blumenfeld et al., 1999), indicating that almost all FD carriers share a common ancestor. The remaining six chromosomes revealed the existence of three other haplotypes: minor haplotype 1, detected in two unrelated families, minor haplotype 2 present in three families, and minor haplotype 3 in only one family. Importantly, in all cases these haplotypes were observed in individuals that were compound heterozygotes for the major haplotype.

\section{FD major haplotype}

With the candidate gene mapped to a $471 \mathrm{~kb}$ interval (Blumenfeld et al., 1999), two research groups independently screened for mutations by performing overlapping RT-PCR on mRNAs encoded by this region, using control and FD patient-derived lymphoblast and fibroblast cell lines. Primers to the transcript that encodes IKBKAP (inhibitor of kappa light polypeptide enhancer in B cells, kinase complex-associated protein, NCBI Reference Sequence: NM_003640.3, with mRNA length of 6129 bp) generated the predicted $218 \mathrm{bp} \mathrm{RT-PCR} \mathrm{product} \mathrm{using} \mathrm{mRNAs} \mathrm{from}$ control cells, and a 144 bp product when FD mRNA was used. Sequence comparison between the FD and control RT-PCR products revealed that the IKBKAP mRNA derived from FD cells does not contain exon 20. Sequence analysis of $I K B K A P$ gene from FD chromosomes, revealed a $\mathrm{T}$ to $\mathrm{C}$ transition in position 6 of the donor splice-site of intron 20. While normal IKBKAP encodes a full-length protein (IKAP) of about $150 \mathrm{kDa}$, the FD mutation, (IVS20+6T $>C$ ), results in the generation of an mRNA in which exon 20 (74 bp) is spliced out, causing a frameshift that results in a premature stop codon (Anderson et al., 2001; Slaugenhaupt et al., 2001; IKAP, NCBI Reference Sequence: NP_003631.2, protein length 1332 aa). Significantly though, in FD patients there is variable tissuespecific skipping of exon 20, leading to reduced IKBKAP full-length mRNA levels in all tissues, with nervous system tissues displaying the most severe reduction in exon 20 inclusion (Figure 1; Cuajungco et al., 2003; Hims et al., 2007). Although the predicted truncated IKAP protein of $79 \mathrm{kDa}$ has been detected in FD-derived lymphoblasts (Anderson et al., 2001), other groups failed to detect such product in other FD cell lines or tissues. It is currently believed that at least part of the abnormally spliced IKBKAP transcripts is degraded by nonsense-mediated mRNA decay (NMD), as demonstrated in FD-derived olfactory stem cells (Boone et al., 2010) and that the truncated protein might be unstable due to its inability to dimerize (Xu et al., 2015).

To determine the underlying mechanism leading to alternative splicing and preferential skipping of exon 20 in neuronal tissues, an in silico analysis was performed to identify potential sequences that might also be involved in the process. Computational analyses showed that sequences 5' and 3' of exon 20, and the sequence of exon 20 itself provided an environment where the definition of exon 20 is weakened (Ibrahim et al., 2007). In addition, differentiation of FD-derived induced pluripotent stem cells (iPSCs) into neuronal cells resulted in further reduction of exon 20 inclusion compared to non-differentiated cells, suggesting that the splicing machinery changes as the cells differentiate into neurons (Lee et al., 2009).

\section{FD minor haplotypes}

The most common minor haplotype (minor 2) (Blumenfeld et al., 1999) is caused by a $\mathrm{G}$ to $\mathrm{C}$ transversion in exon 19 of the IKBKAP gene. The mutation results in both an arginine to proline substitution in aminoacid residue 696 of IKAP (R696P) and the disruption of a consensus serine/threonine kinase phosphorylation site, resulting in reduced phosphorylation at this site (Anderson et al., 2001). FD minor haplotype 2 mutation is rare in the Ashkenazi Jewish population, with a carrier frequency estimated to be less than 1 in 2,500 and has only been detected in four patients, but never in homozygosity (Dong et al., 2002). Minor haplotype 1 is caused by a $\mathrm{C}$ to $\mathrm{T}$ transition in exon 26 of the IKBKAP gene, resulting in a pro914-to-leu (P914L) substitution presumed to impair phosphorylation at this site. The mutation was identified in a patient of mixed ancestry, and was inherited from a non-Jewish 

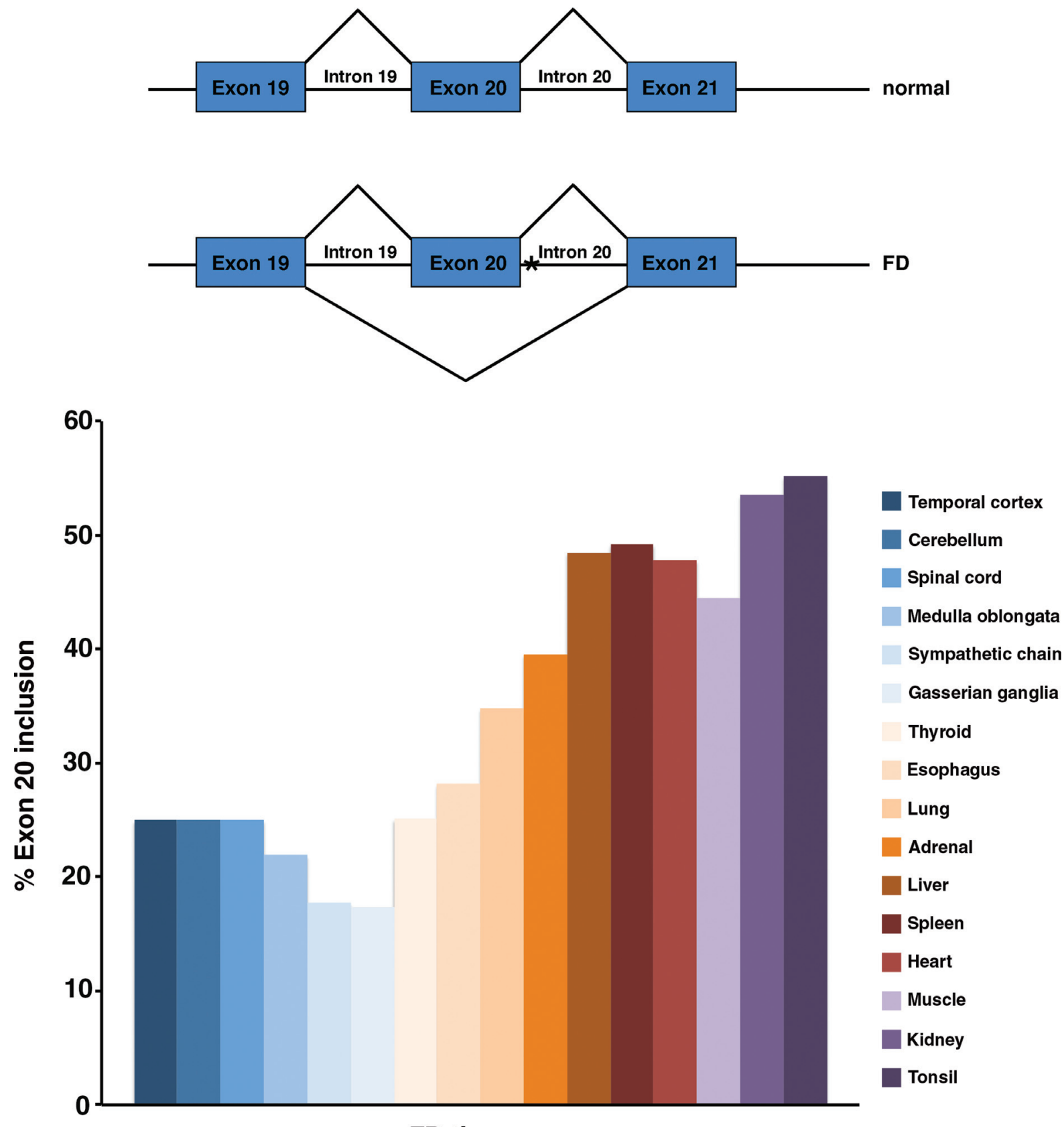

\section{FD tissues}

Figure 1 - FD major haplotype mutation leads to tissue-specific exon 20 skipping in Ikbkap mRNA. (A) Schematic representation of Ikbkap normal and FD alleles. The FD major haplotype point mutation in position 6 of intron 20 is indicated by an asterisk (*). (B) Graphic representation of percentage of exon 20 inclusion in Ikbkap mRNA from FD tissues. (The graph represents a compilation and adaptation of the data presented by Cuajungco et al., 2003 and Hims et al., 2007). Note that neuronal tissues (represented in different shades of blue) consistently show severely reduced levels of exon 20 inclusion.

mother (Leyne et al., 2003). The phenotype caused by these mutations is currently unknown. The mutation responsible for minor haplotype 3 has not yet been characterized.

\section{Genetic testing and current trend of FD population}

With the identification of the mutation responsible for most FD cases, carrier testing began. Carrier testing, based on DNA analyses, is available for the two most common mutations (major haplotype and minor haplotype 2), with an accuracy of $99 \%$. In 2009, only five new FD cases were diagnosed in the world, representing a major reduction in new cases, considering that 15 or 20 were diagnosed per year in the 1990s (Couzin-Frankel, 2010).

Although the FD population at this moment is relatively small, there is still no cure for the existing patients, and the mechanisms underlying the disease are still poorly understood, precluding the development of more efficient therapies. In addition, since FD shares many similarities 
with other neuropathies, understanding the mechanisms of the disease may shed light into other related disorders and increase our understanding of normal peripheral and central nervous system development and maintenance.

\section{Clinical aspects and pathological findings}

Although FD is genetically homogeneous and fully penetrant, clinical and pathological aspects of the disease are variable among individuals, and largely dependent on the age of the patient.

\section{Clinical Presentation}

FD babies are born significantly smaller than their unaffected siblings with births weights ranging from 70 to $90 \%$ of the normal range, indicative of intrauterine growth retardation (Axelrod and Dancis, 1973). Poor suck and uncoordinated swallow is observed in $60 \%$ of FD infants, and, together with a high metabolism, can lead to failure to thrive and malnutrition. In fact, FD children and adolescents display very low fat content, even with high caloric intake. Difficulty swallowing may persist in older children, and appears to be the underlying cause of excessive drooling, a prominent feature of FD patients (Margulies et al., 1968, Wolff et al., 2002). Along with dysphagia, FD patients also display dysarthria due to oral incoordination (Gold-von-Simson and Axelrod, 2006). FD infants are typically hypotonic, and the average age for independent walking is about 26 months of age. Other gross milestones, including sitting unsupported, rolling over, and jumping are also significantly delayed. Decreased deep tendon reflex is also a typical characteristic in FD patients. Several of these features, including poor suck and uncoordinated swallow, and dysphagia have been attributed to either brainstem dysfunction or reduced muscle innervation and control. Hypothalamic neuroendocrine dysfunction has been hypothesized as a possible explanation for poor weight gain.

Although most FD patients appear to have normal intelligence, in general they tend to be literal and have difficulty extrapolating, and visual intellect often exceeds verbal abilities (Welton et al., 1979). About 30\% of FD children have signs of attention deficit disorder (ADD) characterized by short attention span and easy distractibility. Emotional lability is also among the prominent features of FD, and intensifies during episodes of crisis (see below). All these characteristics suggest central nervous system impairment.

FD patients share an unusual facial appearance, described as "trigonal face" with facial asymmetry (Riley et al., 1949; Axelrod and Pearson, 1984). Cephalometric measurements showed that in FD patients the maxilla and mandible are retrognathe to the cranial base, a feature that is significantly more pronounced in the mandible. In addition, horizontal mandibular growth is also distinctive in FD. Together, these alterations give the impression of small jaws, and may contribute to difficulties in oral coordination and speech (Mass et al., 1998). It has been suggested that chronic progressive denervation leading to differences in coordinated muscle function might be the primary cause of abnormal facial expression.

The most common orthopedic manifestation in FD is spinal deformity, with a prevalence of $48 \%$ at the age of 10 , and $86 \%$ at the age of 15 . About $50 \%$ of the spinal deformities are scoliosis only, $44 \%$ are kyphoscoliosis, and the remaining 4\% kyphosis only (Kaplan et al., 1997; Bar-on et al., 2000; Laplaza et al., 2001). Charcot joints and foot deformities (including equinovarus and cavovarus) develop during childhood in about $10-15 \%$ of FD patients (Bar-on et al., 2000). In addition, FD patients sustain a much higher incidence of fractures compared to the normal age-matched population ( $63 \%$ versus $34 \%$, respectively), most of them occurring before the time of skeletal maturation. Intriguingly, the number of fractures per individual is also higher than in the general population, despite the fact that FD children and adolescents are significantly less active than normal age-matched individuals. Progressive denervation is believed to be the cause of spinal deformity, while reduced pain perception is generally thought to be the underlying reason for increased fractures.

Ataxic gait is also one of the hallmarks of FD. FD patients adopt a wide stance, and exhibit unsteady walking, often requiring assistance to prevent falling when turning. The ataxia progressively worsens over time: by the age of 20 , about $5 \%$ of the patients require walking aids, and the need progresses linearly so that by the age of 40 , about $30 \%$ of the patients require assistance for walking (Bar-On et al., 2000; Macefield et al., 2011). Cerebellar dysfunction or loss of muscle spindle sensory afferents leading to reduced proprioceptive acuity have been proposed as possible underlying causes of ataxic gait (Anderson et al., 2001; Macefield et al., 2013).

A smooth tongue is observed in virtually all FD patients and represents one of the cardinal features of FD. In infants, the number and size of fungiform papillae on the tongue are already reduced (Pearson et al., 1970), and fungiform papillae cannot be observed by the naked eye in older patients (Riley and Moore, 1966). The absence of filiform papillae, the reduced number and rudimentary development of fungiform papillae, together with the absence of taste buds, give the tongue a smooth appearance (Goldberg et al., 1968; Pearson et al., 1970).

In FD, decreased temperature and pain perception results in unrecognized burns and injuries. Temperature and pain perception are already impaired in early childhood in most FD patients, but marked variability is observed between individuals of the same age group. In a study involving $75 \mathrm{FD}$ patients, mild temperature perception impairment was observed in about $20 \%$ of the patients examined, and severe impairment in about $47 \%$ of the cases. No significant differences were noted between 
young and older individuals and temperature perception did not worsen in a five-year follow-up. In the same group of patients, pain perception was normal in $20 \%$ of the young patients, and severely impaired in about $12 \%$ of the remaining patients of this age-group. Significantly, all older patients exhibited impaired pain perception, with severe impairment observed in more than $30 \%$ of the cases of this age group; in addition, in a five-year follow-up there was also a tendency for worsening (Axelrod et al., 1981). Together, these observations indicate that the increased threshold for temperature perception does not change over time in FD patients, while there is a marked progression in impairment of pain perception. The decrease in pain and temperature perception are indicative of sensory deficits.

Ophthalmologic problems are also observed in FD and become worse as the patient population age. One of the main characteristics of FD is the absence of overflow emotional tears, and alacrima that may lead to corneal abrasions. Absent corneal reflexes, and abnormal pupillary response to metacholine are also typical findings (Axelrod, 2006). In addition, progressive optic nerve atrophy and visual decline are observed in a large fraction of FD patients, starting at the end of the first decade of life. In some patients, visual acuity and color vision deteriorate over time, likely due to progression of optic nerve damage (Rizzo 3rd et al., 1986; Groom et al., 1997; Mendoza-Santiesteban et al., 2012; Mendoza-Santiesteban et al., 2014).

Cardiovascular abnormalities are also prominent in FD patients. Orthostatic hypotension often starts in school-age children and become more pronounced with increasing age, in part due to the increase in height. In FD patients, postural hypotension, characterized by a severe decrease in blood pressure without compensatory increase in heart rate, results in episodes of lightheadedness, dizziness and weakness of the legs (Axelrod, 2004). Supine hypertension is also common in adolescents and becomes more frequent in older patients. FD patients are hypertensive (SBP $>140 \mathrm{mmHg}$ ) about $20-50 \%$ of the time (Norcliffe-Kaufmann et al., 2010; Carroll et al., 2012) and older FD patients have a high incidence of left ventricular atrophy, a sign of end-organ target damage due to chronic hypertension. Renal function also deteriorates as the patients get older, with $20 \%$ of adult patients having reduced renal function. The severity of renal disease parallels the extent of blood pressure variability, and most likely happens as a secondary consequence of chronic hypertension (Norcliffe-Kaufmann et al., 2013). The mechanisms leading to blood pressure variability and hypertension in FD have been sequentially attributed to central autonomic dysfunction (Solitare, 1991; Gold-von Simson and Axelrod, 2006), to sympathetic and parasympathetic efferent baroreflex dysfunction (Hilz et al., 1999; Stemper et al., 2004; Goldstein et al., 2008), or, more recently, to afferent baroreflex failure due to vagal withdrawal (NorcliffeKaufmann et al., 2010; Carroll et al., 2012).
Vomiting attacks (gastroesophageal reflux), often associated with hypertension, tachycardia, diffuse sweating, and red blotching of the skin consist the most prominent manifestation of FD, occurring in about $65-80 \%$ of FD patients, and can occur either intermittently as a response to physical or emotional stress, or daily in response to the stress of arousal. This "constellation of signs" is commonly referred to as "dysautonomic crisis" and is the leading cause of frequent hospitalizations of FD children (Axelrod, 2004; Gold-von-Simson and Axelrod, 2006). Although the pathophysiology of FD crisis is still not fully understood, it appears to involve central autonomic dysfunction (Anderson and Rubin, 2005; Cheishvili et al., 2014b)

Pulmonary problems are also common in FD patients. Aspiration due to misdirected swallow is the major cause of pneumonia in FD. If gastroesophageal reflux is also present, the risk for aspiration increases significantly and repeated pulmonary aspiration eventually leads to pulmonary disease (Gold-von-Simson and Axelrod, 2006). Breathholding episodes, usually triggered by excitement, are also frequent, occurring in about $63 \%$ of FD patients, and can happen from 18 months of age up to 6 years of age. Prolonged breath-holding can be severe, due to insensitivity to hypoxia, and can lead to secondary complications. These episodes are thought to represent a type of seizure activity (Axelrod, 2004; Gold-von-Simson and Axelrod, 2006).

\section{Pathological, physiological and molecular findings}

As mentioned above, several of FD major features could potentially be explained by central nervous system and/or peripheral nervous system abnormalities. Most of the pathological and physiological studies on FD have therefore focused on these two systems (Figure 2).

\section{Central nervous system}

In initial reports dating from 1945 to 1964, central nervous system (CNS) pathology was described in four FD patients ranging from 2 to 18 years of age. In all four cases, demyelination of the reticular formation of the pons and medulla were consistent findings. In addition, demyelination of spinothalamic tracts, and loss of cranial nerve nuclei of the brain stem were also reported in two cases (Aring and Engel, 1945; Cohen and Solomon, 1955; Brown et al., 1964). Other abnormalities, including thalamic degeneration and brain abscesses were observed in only two cases, but appeared to be secondary to episodes of hypoxia or inflammation (Solitare, 1991). However, subsequent investigations in an additional four FD patients (ranging from 10 months of age to 31 years of age) failed to detect any signs of demyelination or other signs of neuronal loss or atrophy in the CNS (Pearson et al., 1970; Yatsu and Zussman, 1964; Solitare and Cohen, 1965; Fogelson et al., 1967).

Due to the apparent inconsistency of CNS findings in FD patients, and the concomitant realization that not only several of the FD features could be explained by peripheral 


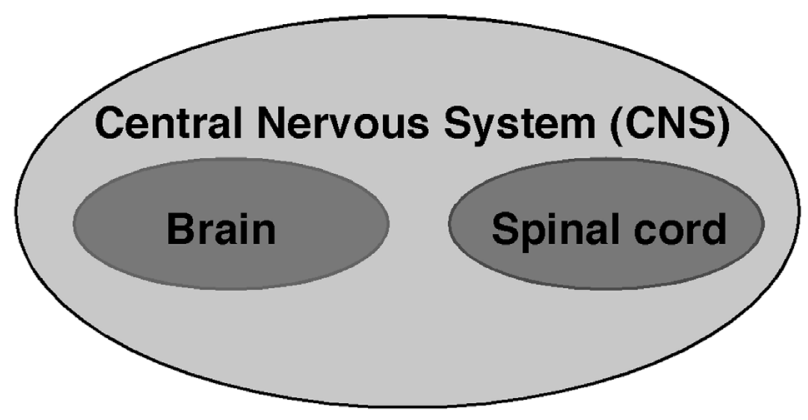

CNS

Integrates inputs

and commands

response

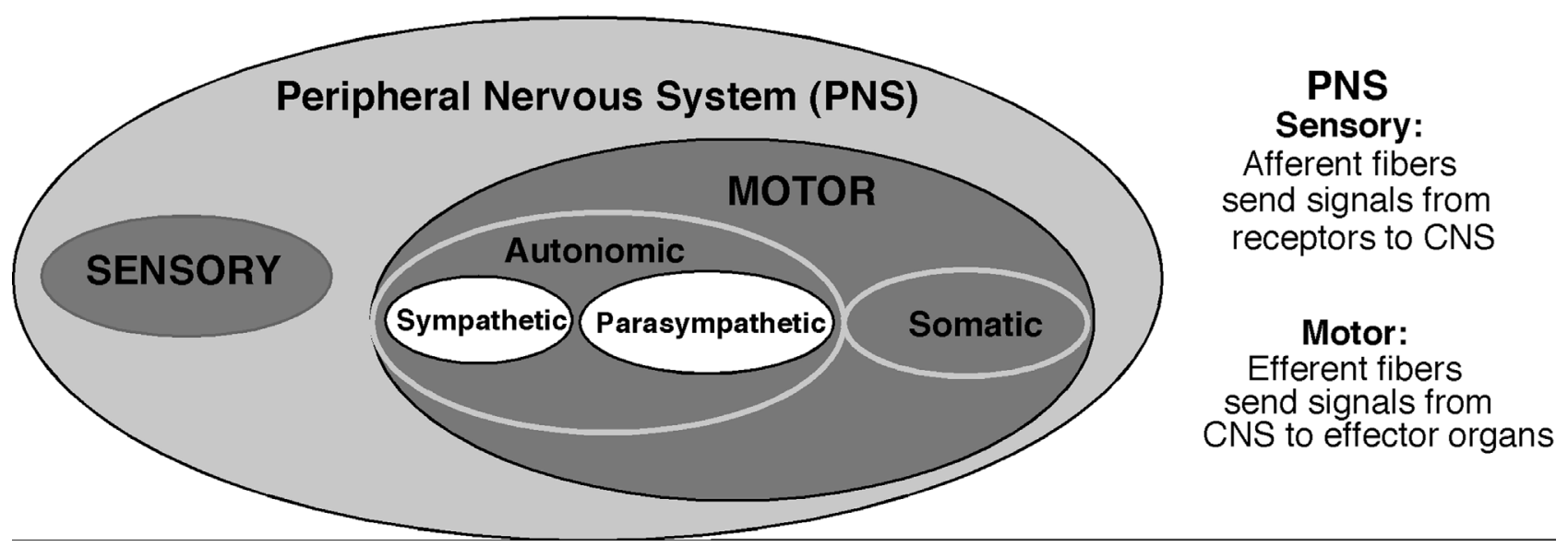

Figure 2 - Simplified schematic representation of the Nervous System. The Central Nervous System (CNS), consists of brain and spinal cord, receives inputs from the Peripheral Nervous System (PNS) afferent (sensory) fibers, integrates the signals and commands the response via the efferent (motor) fibers of the PNS.

sensory and autonomic disturbances, but also that peripheral nervous system appeared more consistently altered in FD (see below), subsequent studies focused almost exclusively on the evaluation of peripheral nervous system anomalies in FD patients, with a nearly complete disregard to CNS evaluation for almost 40 years.

More recently however, additional studies have provided a strong indication that the CNS is also compromised in FD. For instance, visual impairment in FD patients become noticeable after the first decade of life, and are associated with progressive optic atrophy and with predominant loss of papillomacular nerve fibers (Rizzo 3rd et al., 1986; Groom et al., 1997; Mendoza-Santiesteban et al., 2012, 2014). Analyses of brainstem auditory evoked potentials, as well as blink and jaw jerk reflex in FD patients also strongly suggest brainstem dysfunction (Lahat et al., 1992; Gutierrez et al., 2015; Tellez, 2015). MRI studies showed abnormalities that suggest compromised myelination as well as grey matter and white matter micro-structural damage in FD brains. Abnormal findings are more evident in optic radiation, middle cerebellar pedunculum, and frontal lobe (Axelrod et al., 2010). Significantly, analyses of FD brains showed that the levels of several transcripts and their respective proteins that are involved in myelination are severely reduced in FD brains compared to age-matched healthy individuals (Cheishvili et al., 2007). These obser- vations indicate that central nervous system abnormalities indeed contribute to FD clinical findings.

\section{Peripheral nervous system}

\section{Autonomic nervous system}

In one of the first reports, degenerative pigmentary changes and vacuolization in the cytoplasm were observed in thoracic and pelvic sympathetic ganglia of two young FD siblings, ages 2 and 8 (Brown et al., 1964). Subsequent work in three additional young FD infants (ranging from 10 months to 2 years of age) confirmed these initial findings (Solitare and Cohen, 1965; Freytag and Lindenberg, 1967; Pearson et al., 1970). Post-mortem analyses performed in two of these infants revealed that in the cervical and thoracic sympathetic ganglia several neurons were small, and overall neuronal numbers were reduced, estimated to be around 30\% of normal (Freytag and Lindenberg, 1967; Pearson et al., 1970; Solitare, 1991). Degenerative changes with signs of inflammation were also observed (Pearson et al., 1970). Quantitative analyses performed in adult FD patients revealed that the mean volume of superior cervical ganglia ( $\mathrm{SCG}$ ) is reduced to $34 \%$ of the normal range, neuronal density to $37 \%$ of normal, with neuronal numbers as low as $10 \%$ of controls, indicating progressive loss of neuronal cells with age (Pearson and Pytel, 1978). Immunohistochemistry for tyrosine hydroxylase (a rate- 
limiting enzyme of catecholamine biosynthesis) demonstrated that although there was a severe depletion in SCG neurons, the remaining neurons expressed higher levels of tyrosine hydroxylase compared to controls, which has been interpreted as being part of a compensatory mechanism (Pearson et al., 1979). These analyses clearly indicate that sympathetic neurons are reduced in numbers and are morphologically abnormal in FD already at early age, and it is currently assumed that intrauterine development of sympathetic ganglia is severely compromised in FD.

Consistent with the reduction in neuronal numbers in sympathetic ganglia, ultrastructural studies of peripheral blood vessels also demonstrated the absence of autonomic nerve terminals. In addition, catecholamine metabolism is altered in FD patients (Smith et al., 1963), and other physiological studies indicate that sympathetic deficits also lead to cardiac hypo-innervation (Goldstein et al., 2008).

In the parasympathetic system, the sphenopalatine ganglion is majorly compromised, with a significant reduction of neuronal numbers, averaging $20 \%$ of controls. The ciliary ganglion on the other hand displays only a mild reduction in total neuronal numbers (Pearson and Pytel, 1978).

Sympathetic and parasympathetic denervation and dysfunction are consistent with several of FD clinical features, including defective lacrimation, impaired pupillary reflex, impaired body temperature control, skin blotching, and excessive sweating. Hypertension and postural hypotension have also been attributed to sympathetic deficits, although this is currently under discussion.

\section{Sensory nervous system}

Neuronal numbers in dorsal root ganglia (DRG) are already diminished in young FD patients, and can be as low as $10-20 \%$ the numbers of normal age-matched individuals (Pearson et al., 1978), although extensive variability has been observed between individuals (Fogelson et al., 1967; Solitare, 1991). More consistently, demyelination of the posterior columns (dorsal columns) of the spinal cord has been demonstrated in most post-mortem analyses (Fogelson et al., 1967; Pearson et al., 1978; Solitare, 1991). The finding of severe depletion of DRG neurons early postnatally is suggestive of impaired development during embryogenesis. However, degenerative changes in sensory ganglia (nodules of Nageotte) have been demonstrated in at least some of the cases, suggesting that progressive degeneration also occurs postnatally (Pearson et al., 1970, 1978).

Biopsies from the back and calf of FD patients revealed significant loss of nerve fibers in the epidermis and subepidermal neural plexus, with epidermal nerve fibers (ENF) densities averaging about $12-15 \%$ that of controls. In particular, sensory (substance $\mathrm{P}$ (SP) and calcitonin gene-related peptide (CGRP) positive) nerve fibers were virtually absent in FD biopsies, indicating significant loss of sensory skin innervation. In contrast, vasoactive intestinal peptide (VIP) staining, usually absent in normal subepi- dermal plexus, was significantly increased. In addition, a significant number of empty Schwann cell sheaths were also observed, indicating recent denervation (Hilz et al., 2004). The presence of VIP staining and empty Schwann cell sheaths is indicative of inflammation, ongoing denervation, with some capability for regeneration, consistent with the clinical observation that FD is a progressive neurodegenerative disorder. The decreased unmyelinated nerve content with virtual absence of CGRP and SP immunostaining is compatible with the decrease in pain and temperature perception.

Sural nerve biopsies from FD patients exhibit a very consistent pattern that also distinguishes FD from all the other HSANs. Compared to normal individuals, the sural nerve of FD patients has diminished fascicular area $(50 \%$ the area of controls), displays severe depletion of unmyelinated axons, and of small myelinated fibers. As observed in skin biopsies, there is also a significant number of empty Schwann cell sheaths and occasional presence of macrophages, indicative of ongoing axonal loss (Aguayo et al., 1971; Pearson et al., 1975; Guzzetta et al., 1986).

Histopathological analyses from eight FD patients and age-matched controls demonstrated that in FD there is an extreme paucity in the geniculate ganglion neuronal numbers, as well as a significant reduction in neurons in the vestibular ganglion (cranial ganglion VIII), albeit to a lesser extent (Tokita et al., 1978). Since the geniculate ganglion innervates the tongue fungiform papillae taste buds, this reduction in neuronal numbers is consistent with both the reduced sensory innervation and the absence of taste buds demonstrated in FD tongue (Pearson et al., 1970), which require sensory innervation for their proper development and survival. Histopathological changes in the vestibular ganglion may in turn explain the poor balance and coordination of FD patients (Tokita et al., 1978). So far, no histopathological analyses have been performed in other cranial sensory ganglia in FD.

Development of the peripheral nervous system begins with delamination of neural crest cells (NCC) from the neuroectoderm. These cells give rise to sympathetic ganglia and most of the sensory ganglia, including dorsal root ganglia (DRG) and trigeminal ganglia. In parallel, cells derived from the cranial placodes also delaminate and will contribute to the cranial sensory ganglia, geniculate, petrosal and nodose ganglia (Steventon et al., 2014). Cells derived from these two origins then either coalesce or migrate to their respective final locations where they undergo differentiation into several neuronal subtypes. Virtually all neurons of the peripheral nervous system undergo programmed cell death shortly after the time of initiating functional innervation. Survival of neurons during the period of innervation depends on neurons acquiring access to a limited supply of neurotrophic factors expressed by the innervated "target field" and retrogradely transported to the neuronal cell body. For instance, the requirement of nerve 
growth factor (NGF) as a target field-derived survival factor for sympathetic and sensory nociceptive neurons is well established (Indo, 2014). In the developing rat, NGF expression levels are highest in tissues that are highly innervated by sympathetic fibers (Shelton and Reichardt, 1984), while sensory innervation correlates with NGF expression in the developing skin and spinal cord (Davies et al., 1987; Elkabes et al., 1994). Similarly, other types of neurons require appropriate supply and signaling by other neurotrophins. Neurotrophic support derived from the target field is also required throughout postnatal life for maintenance of innervation and neuronal survival. Hence, disturbance of any of these steps (or a combination of them) could result in depletion of sensory and/or sympathetic neurons and loss of innervation in FD.

\section{IKAP Cellular functions: implications for PNS deficits}

Historically, IKAP was identified as a novel $150 \mathrm{kDa}$ protein that interacts with cytokine-activated $\mathrm{I} \kappa \mathrm{B}$ kinase (IKK) complexes, which participate in the activation of the transcription factor NF- $\mathrm{KB}$, hence the name IKAP, for "IKK complex associated protein". IKAP was initially shown to bind directly to IKK-alpha and IKK-beta and, acting as a scaffold protein, to assemble IKKs into an active kinase complex (Cohen et al., 1998). Investigations by other research groups confirmed that IKAP is mostly localized in the cytoplasm, but failed to identify IKAP as a regular member of IKK complexes and further demonstrated that IKAP is not required for NF- $\mathrm{KB}$ signaling (Krappmann et al., 2000). Since then, several other cellular functions of IKAP have been unraveled. IKAP, either as part of the Elongator complex (see below) or possibly acting independently, has been shown to interact with a variety of nuclear and cytoplasmic proteins and to play a role in tRNA wobble uridine modification (Lin et al., 2013; Karlsborn et al., 2014; Laguesse et al., 2015), cytosolic stress signaling (Holmberg et al., 2002), DNA repair (Li et al., 2009), and zygotic paternal DNA demethylation (Okada et al., 2010), among others. However, so far the link between any of these above-mentioned functions with FD pathology and in particular with PNS deficits still remain to be elucidated.

This section will therefore focus only on the cellular functions of IKAP that have been more thoroughly investigated and have led to insights into the mechanisms underlying abnormal PNS development and function in FD.

\section{IKAP is a member of the Elongator Complex}

Sequence comparison between species showed that IKAP is the human homologue of the yeast elongator protein 1 (ELP1), one of the six subunits of the Elongator complex, which was initially identified as a complex essential for RNA polymerase II (RNA pol II) transcription elongation (Otero et al., 1999). Purification and characterization of the human Elongator complex revealed that, as in yeast, the human holo-Elongator complex is also composed of six subunits, and confirmed that IKAP is an integral component of the core of the Elongator complex, which is composed of three subunits hELP1/IKAP, hELP2 and hELP3 (Hawkes et al., 2002). Within the Elongator complex, ELP1/IKAP appears to act as a scaffold protein required for Elongator assembly and also serves to dock other proteins that regulate the Elongator function, whereas ELP3 is the catalytic subunit and acetylates histones H3 and H4 (Glatt and Muller, 2013). Consistent with these observations, IKAP protein is also observed in the nucleus, and decreased IKAP expression in FD patient-derived fibroblasts leads to reduced ELP3 levels, reduced Elongator binding, and decreased histone $\mathrm{H} 3$ acetylation in the coding region of genes that are downregulated in FD cells. Moreover, RNA pol II density is significantly decreased at the 3' end of these genes, but not at the promoter region, implying that the Elongator complex is not required for recruitment of RNA pol II to the promoter region, but affects primarily transcript elongation (Close et al., 2006). These findings suggested that transcriptional dysregulation might be the underlying cause of the deficits observed in FD.

\section{Decreased IKAP expression impairs cell migration}

With the finding that IKAP is part of the RNA pol II transcriptional Elongator complex, much of the subsequent work focused on comparative transcriptome or microarray analyses, aiming at identifying pathways that are affected by IKAP depletion. Using this approach, it was found that gene transcripts involved in cell migration are significantly down-regulated in a variety of FD patient-derived cells, including fibroblasts (Close et al., 2006), induced pluripotent stem cells (iPSCs, Lee et al., 2009), and olfactory ectomesenchymal stem cells (hOE-MSCs, Boone et al., 2010), as well as in IKBKAP siRNA- transfected cell lines including HeLa (Close et al., 2006), and SHSY5Y neuroblastoma cells (Cohen-Kupiec et al., 2011).

Consistent with the down-regulation of transcripts involved in cell migration, cell migration defects were demonstrated in vitro for all of the above-mentioned FDderived cell types. These observations reinforced the notion that FD peripheral nervous system abnormalities might be the result of impaired migration of neural crest cell (NCC) precursors. In vivo studies however, demonstrated that inactivation of the IKBKAP gene in NCC precursors, either in the chick or in the mouse, does not impact their migration. In the chick, down-regulation of IKAP expression in NCC by Ikbkap small-hairpin RNA (shRNA) or Ikbkap si-RNA microinjection or electroporation revealed that IKAP function is not necessary for either NCC migration or DRG formation (Hunnicutt et al., 2012; Abashidze et al., 2014). Similarly, conditional inactivation of the mouse Ikbkap gene in pre-migratory and migratory NCCs does not affect NCC migration, pathfinding, or formation of DRG and 
sympathetic ganglia (George et al., 2013; Jackson et al., 2014).

Together, these findings indicate that although reduction or loss of IKAP expression results in impaired cell migration, this impairment is either compensated by external signals in vivo, or are not severe enough to have a biological significance. In any case, it is clear that peripheral nervous system abnormalities in FD are not caused by impaired cell migration.

IKAP and cytoskeleton organization: impact on neurite outgrowth and intracellular transport.

A much more consistent and biologically relevant cellular function of IKAP appears to be its requirement for cytoskeleton actin filament and microtubule organization and neurite outgrowth. Cytosolic IKAP was shown to copurify with filamin A in rat cerebellar granule neurons, and immunohistochemistry for IKAP and filamin A showed that they co-localize with membrane ruffles. Depletion of IKAP in these cells did not decrease the expression of genes involved in cell migration, but resulted in actin cytoskeletal disorganization and reduced cell migration in vitro (Johansen et al., 2008). These observations suggest that cell migration defects in cells depleted of IKAP may be linked to cytoskeleton disturbances instead of transcriptional dysregulation.

Immunostaining of FD-derived fibroblasts for the cytoskeleton component $\alpha$-tubulin revealed disorganization of the microtubules (MTs) that resulted in aberrant cell shape. Similar results were obtained with neuroblastoma cells after down-regulation of IKAP. Moreover, in neuroblastoma cells, $\alpha$-tubulin was shown to be concentrated in one pole of the cells resulting in abnormal process formation, with concomitant up-regulation of the MT-destabilizing protein SCG10 (STMN2). Significantly, RNAimediated SCG10 downregulation in FD-derived fibroblasts rescued cytoskeleton organization (Cheishvili et al., 2011).

Microtubules (composed of alpha and beta-tubulin dimers) are particularly abundant in neurons, and are involved in multiple intracellular processes, including developing and maintaining cell shape, intracellular transport, cell signaling, and neurite extension (Kapitein and Hoogenraad, 2015). In vivo studies confirmed the need of IKAP for all these processes.

In the developing mouse brain, Ikbkap silencing in migrating projection neurons results in altered cell morphology and absence of growing apical dendritic tree and processes. In culture, Ikbkap null cortical neurons also exhibited reduced dendrite length and branch numbers (Creppe et al., 2009). Interaction of IKAP with ELP3 appears to be necessary to regulate alpha-tubulin acetylation, a process that appears to be required for branching of postmigratory projection neurons (Creppe et al., 2009; Nguyen et al., 2010). Importantly, purified ELP3-enriched fraction promotes $\alpha$-tubulin acetylation invitro suggesting a direct role of IKAP and ELP3 in this process (Creppe et al., 2009).

Down-regulation of Ikbkap in chick neural crest cell precursors lead to marked disruptions in axonal projections of DRGs (Hunnicutt et al., 2012; Abashidze et al., 2014). In particular, the major disturbances are observed in the branching and positioning of the distal processes, while the positioning of the main nerves do not appear to be affected. In growth cones of control DRG cultures, IKAP was shown to co-localize with stable tubulin fibers, and to a lesser extent along dynamic tubulin fibers. Significantly, depletion of IKAP in cultured DRGs results in disturbance of tubulin structures (Abashidze et al., 2014). Similarly, in mice, inactivation of Ikbkap gene in neural crest cells leads to 35 to $40 \%$ reduction in total neuronal numbers in DRGs (George et al., 2013; Jackson et al., 2014), and reduction in sympathetic neuronal numbers between $42 \%$ loss (Jackson et al., 2014) to $70 \%$ loss (George et al., 2013). Similar to chicks, loss of IKAP in neural crest cells in mice leads to a significant reduction in sympathetic and sensory target tissue innervation, likely due to abnormal axonal branching (Jackson et al., 2014).

Together these results indicate that IKAP is required for axonal branching and fine-tuning of the innervation process, and suggest that loss of DRG and sympathetic neuronal cells in FD is likely a consequence of failed innervation of target tissues.

Recently, it has also been shown that downregulation of IKAP in cultured chick DRG neurons results in decreased NGF intracellular signaling. Moreover, IKAP was also shown to interact directly with the motor protein dynein, suggesting that IKAP may also be involved in intracellular transport (Abashidze et al., 2014). These initial findings were further corroborated by transcriptome analyses in neuronal differentiated FD-derived embryonic stem cells as well as in FD embryonic brains (Lefler et al., 2015). In particular, these analyses revealed that in FDderived neurons and embryonic brains synaptic vesicular and neuronal transport genes are directly or indirectly affected by IKAP depletion (Lefler et al., 2015). Significantly, among the five types of HSANs, FD (HSAN III), HSAN IV (caused by mutations in NGF receptor), and HSAN V (caused by mutations in NGF) share several similarities. All these disorders are congenital and are characterized by decreased pain and temperature perception, Charcot joints, decreased skin innervation, and severe depletion of unmyelinated fibers and small myelinated fibers in the sural nerve (Capsoni, 2014). Null mutations for NGF or NGF receptor (TrkA/NTRK1) in mice result in severe loss of sympathetic neurons and nociceptive sensory neurons (Davies, 2000).

Together, these observations suggest that IKAP may play an essential intracellular role in retrograde neurotrophic transport and signaling, and that in addition to im- 
paired target innervation, impaired neurotrophic signaling might also contribute to PNS neuronal cell death in FD.

\section{What does expression of IKAP in the developing embryo tell about FD?}

Up to now, there is limited information regarding the pattern of expression of IKAP during embryogenesis, and although FD appears to be a developmental disorder, it is currently not known what is the tissue-specific pattern of exon-20 skipping during development, since all the information regarding alternative splicing in FD has been performed in adult-derived tissues and cell lines (see above).

Ikbkap mRNA is already detected in early mouse embryos (embryonic day 8.5; E8.5), prior to the formation of NCCs, indicating that IKAP may be involved in other developmental processes as well (Chen et al., 2009; Dietrich et al., 2011). High levels of IKAP expression are later on observed in sensory and sympathetic neuroblasts and in the developing brain, as shown by immunohistochemistry (Creppe et al., 2009; Jackson et al., 2014). RT-PCR analyses also detected low-to-moderate levels of Ikbkap expression in peripheral organs, including heart, kidney, and lungs in developing mouse embryos at mid-to-late gestation (Dietrich and Dragatsis, unpublished results).

In the chick, analysis of the pattern of expression of IKAP was focused exclusively in the developing peripheral nervous system (Hunnicutt et al., 2012; Abashidze et al., 2014). In situ hybridization and immunohistochemistry failed to detect IKAP expression during the period of neural crest migration and DRG formation. Instead, IKAP expression is first observed in nascent and postmitotic neurons, and increases as the neurons mature and differentiate (Hunnicutt et al., 2012; Abashidze et al., 2014). In particular, the increase in IKAP expression in DRGs coincides with the onset of peripheral outgrowth and target innervation (Abashidze et al., 2014). In addition, significant immunolabeling for IKAP was also observed in the developing spinal cord, in particular in the ventral horn motor neurons and the ventricular zone (Hunnicutt et al., 2012), and in primary sympathetic ganglia (Abashidze et al., 2014).

A far more detailed analysis has been performed in the developing rat. In situ hybridization in mid-to-late gestation rat embryos (E15.0 to E21.0) revealed that Ikbkap mRNA is expressed in a wide variety of tissues. At E15.0, Ikbkap mRNA is found in the brain, spinal cord, sensory ganglia, eye retina, liver, and intestinal tract. By E17.0, Ikbkap mRNA begins to be expressed in additional tissues, including the adrenal gland, Merkel cells, salivary glands, lungs, renal cortex, and cartilage. At E21, in addition to the tissues listed above, a high level of Ikbkap expression is also detected in the heart, skin, stomach, and carotid body. Notably, at all stages examined, the highest levels of expression were seen in the dorsal root ganglia, trigeminal ganglia, retina, central nervous system, and kidney cortex (Mezey et al., 2003).

The wide distribution of Ikbkap mRNA expression observed in the developing rat implies that IKAP may play essential roles not only in nervous system tissues but also in non-neuronal cells. In this aspect, it is important to note that expression of IKAP in the kidney correlates well with the relatively high frequency of kidney malformations observed among FD patients, and suggests that a need of IKAP in the kidney may also contribute to kidney disease (Norcliffe-Kaufmann et al., 2013). Expression of IKAP in the retina could explain the selective loss of retina ganglion cells (Mendoza-Santiesteban et al., 2014). Likewise, expression of IKAP in cartilage is consistent with the decrease in bone mineral density observed in FD patients, a possible underlying explanation for the increased frequency of fractures (Maayan et al., 2002), and suggests that IKAP may also be required for bone growth. Finally, and most intriguingly, the presence of Ikbkap mRNA in peripheral target tissues (salivary glands, skin, heart, lungs, stomach) suggests that IKAP may also play an essential role in these tissues. An attractive possibility is that IKAP might be required for adequate production of neurotrophins that are retrogradely transported to neuronal cells at the time of innervation as well as postnatally in order to maintain innervation. This possibility is substantiated by the histopathological changes in the skin of FD patients where there are signs of denervation and re-innervation, and also by the early biochemical findings that suggested that NGF produced by FD-derived fibroblasts cells demonstrates decreased neurotrophic activity (Siggers et al., 1976; Schwartz and Breakefield, 1980; Wrathall, 1986).

\section{Animal models for FD}

The pattern of IKAP expression and the phenotypic features of FD not related to the peripheral nervous system suggest that FD is a complex disease and could actually be viewed as a multiple system disorder. In order to fully understand the pathogenesis of FD and to develop more comprehensive and efficient therapies, animal models that faithfully recapitulate the disease would be greatly advantageous.

\section{Mouse Ikbkap}

The mouse Ikbkap gene is located on chromosome 4 and encodes a 6160 nucleotide long mRNA (NCBI Reference Sequence: NM 026079.3). At the nucleotide level, the mouse Ikbkap mRNA exhibits $77 \%$ identity with the human IKBKAP mRNA (Coli et al., 2001; Cuajungco et $a l ., 2001)$. As in humans, the mouse Ikbkap gene consists of 37 exons, distributed over about $53 \mathrm{~Kb}$ of genomic DNA. Importantly, the donor splice-site sequence altered in FD major haplotype is also conserved in the mouse. The high level of conservation of the gene between human and mou- 
se suggest that the function of the gene is also conserved between species.

\section{Inactivation of lkbkap gene in the mouse}

In an initial attempt to understand the roles of IKAP in embryogenesis and possibly generate a mouse model for the disease, two research groups generated null mutations in the mouse Ikbkap gene. Unexpectedly, it was found that inactivation of the Ikbkap gene in mice results in embryonic lethality, between E10.5 and E11.5 (Chen et al., 2009; Dietrich et al., 2011). Ikbkap null embryos appear grossly normal at E6.5 (Chen et al., 2009), but by E9.5 they display already a significant developmental delay (about $24 \mathrm{hr}$ delay) compared to controls. By E10.5, although mutant embryos reach several milestones of a typical E9.5 embryo (including neural fold closing, turning of the embryo, and development of the first branchial arch) they display poor vascularization of the extraembryonic tissues, anterior cephalic developmental defects, and cardiovascular abnormalities. In particular, development of the forebrain is compromised, and the heart does not develop past an E8.5-like primitive heart. Abnormal heart looping and dilated pericardial sac in null embryos indicate that heart failure is likely the cause of death of Ikbkap null embryos (Dietrich et al., 2011). Consistent with a need of IKAP for heart development, RT-PCR analyses showed that expression of the transcription factors Gata5 and Smad4, which are essential for heart morphogenesis, are significantly down-regulated in Ikbkap null embryos (Dietrich et al., 2011). Homozygosity for an Ikbkap allele lacking exon 20 (Ikbkap $\Delta 20$; Figure 3) also resulted in a similar phenotype, indicating that the truncated IKAP protein does not retain significant biological function (Dietrich et al., 2011).

These analyses indicate that inactivation of Ikbkap results in several severe developmental abnormalities that are not seen in FD. Also, inactivation of Ikbkap in neural crest cell precursors results in cleft secondary palate (Jackson et al., 2014; Dietrich and Dragatsis, unpublished results), a severe developmental malformation that is never observed in FD patients. Keeping in mind that FD has pleiotropic manifestations, and that the IVS20+T $>\mathrm{C}$ mutation in FD patients results in reduced levels of IKBKAP expression in all tissues, it becomes obvious that global reduction and not tissue-specific elimination of Ikbkap expression is required to generate a model for FD.

\section{Mouse models of FD}

So far, all attempts to generate a mouse model for FD by introducing the FD major haplotype mutation in the mouse genome have been unsuccessful.

Slaugenhaupt and collaborators generated a series of transgenic mice carrying different copy numbers of a human IKBKAP bacterial artificial chromosome (BAC) carrying the FD IVS20+6T $>\mathrm{C}$ mutation (FD BAC). Characterization of the splicing pattern of human IKBKAP
mRNA in several transgenic lines by semi-quantitative RT-PCR revealed that they recapitulated faithfully the same tissue-specific splicing pattern seen in FD patients (Hims et al., 2007). As expected, none of the transgenic lines had FD phenotypic features when normal levels of endogenous mouse IKAP protein was expressed. In an effort to elicit an FD phenotype, FD BAC mice were crossed into an Ikbkap null background. Unfortunately, none of the compound FD BAC transgenic/Ikbkap null mice recapitulated the FD phenotype. Although the FD BAC mice do not model FD, they can be used to test in vivo the efficacy of compounds that have the potential to correct the FD splicing defect (Shetty et al., 2011).

Using another approach, Ast and collaborators generated a mouse Ikbkap allele in which exon 20 and its two flanking introns were replaced by the corresponding human FD sequence that contains the IVS20+6T $>\mathrm{C}$ mutation (Bochner et al., 2013). Contrary to what was expected, mice homozygous for this mutation were viable and did not exhibit any of the human FD phenotypes. Quantitative RT-PCR analyses revealed that insertion of the FD human mutation resulted in a different tissue-specific splicing pattern in the mouse compared to what is observed in FD patients. In the mouse, significant skipping of exon 20 occurred in the liver, but not in the nervous system. This differential pattern of exon 20 skipping most likely results from differences in the mechanisms of splicing sequence recognition between the two species.

Other research groups also attempted to generate an FD mouse model by introducing the FD point mutation into the mouse Ikbkap allele and were equally unsuccessful (D. Brenner personal communication; Dietrich and Dragatsis, unpublished results). Although the reasons for this failure are still unclear, it is possible that the sequence and/or size of the introns surrounding the FD point mutation might be the main reason for the technical difficulties, or that differences between the mouse and human splicing machinery might be the underlying impediment for the success of this approach. Since complete inactivation of Ikbkap in mice is embryonic lethal, and FD carriers (heterozygous for the point mutation) expressing $50 \%$ the levels of normal full length IKAP protein are asymptomatic, the generation of a successful FD model likely requires that the level of normal IKAP protein be reduced between 0 and $50 \%$ the normal levels.

Successful FD mouse models were finally developed with the generation of compound Ikbkap ${ }^{\Delta 20 f l o x}$ mice (Dietrich et al., 2012). In practical terms, although the compound mouse does not carry the FD major mutation, molecularly the consequence of the generated mutations is the same: expression of an Ikbkap mRNA lacking exon 20 from the $\Delta 20$ allele and highly reduced wild-type (wt) Ikbkap mRNA levels from a hypomorphic Ikbkap floxed allele due to the loxP insertion interference (Figure 3). 
A
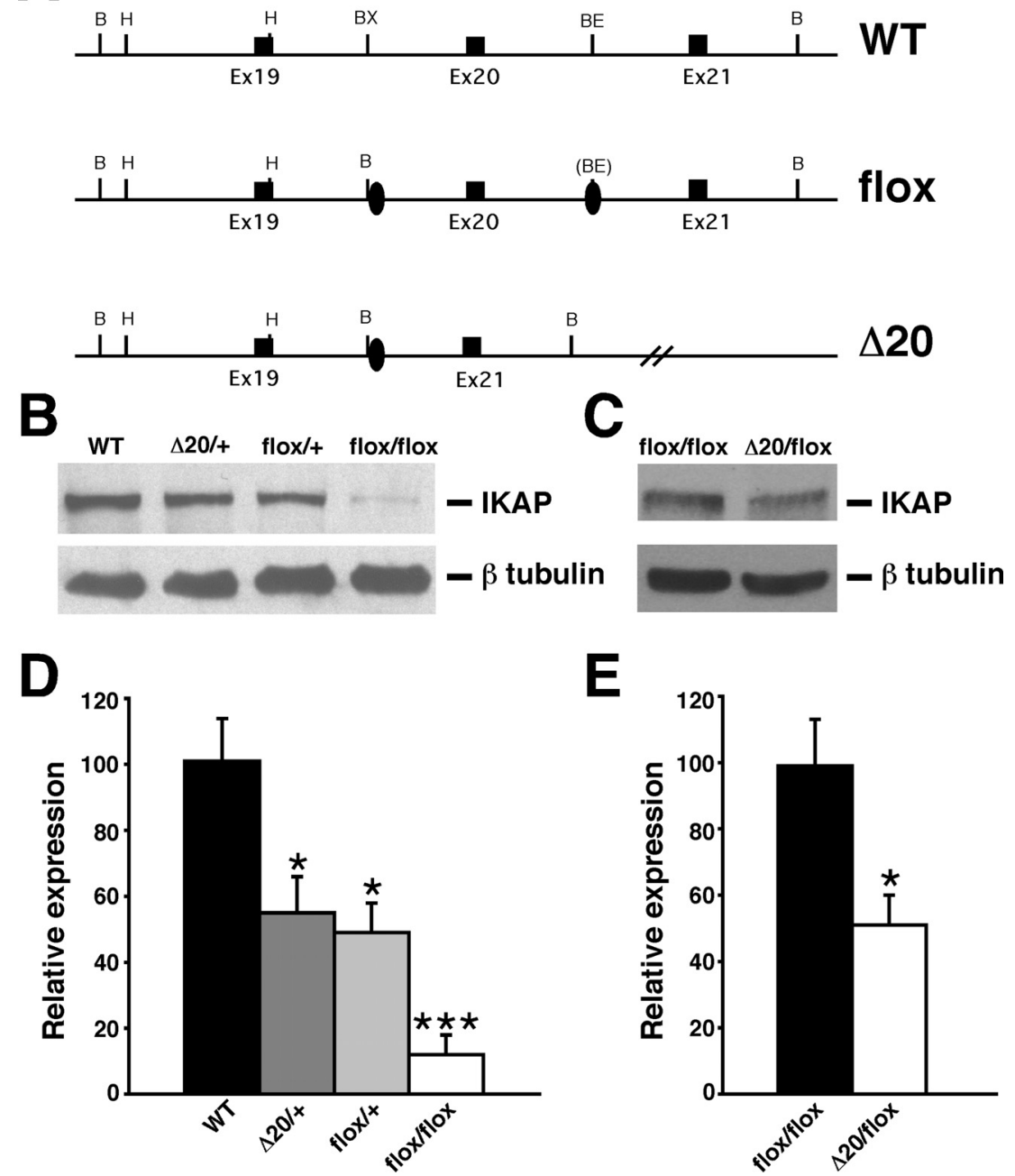

Figure 3 - Generation and molecular characterization of FD mouse models. (A) Schematic representation of wild-type allele (WT), Ikbkap flox allele (flox), and Ikbkap allele lacking exon $20(\Delta 20)$. Exons are represented by black rectangles, and black ovals represent the loxP sites. Restriction sites shown on the schematic are: Bam HI (B), HindIII (H), BstXI (BX) and BstEII (BE). (B) Western blot analyses of total protein lysates from forebrain of 11-month-old WT, Ikbkap ${ }^{\Delta 20 /+}$, Ikbkap ${ }^{\text {flox/4 }}$, and Ikbkap floxflox mice. Upper panel shows detection of IKAP with the polyclonal anti-IKAP antibody (AnaSpec), and lower panel shows anti- $\beta$-tubulin staining for loading control. Note that IKAP protein level is severely reduced in $I k b k a p^{f l o x f l o x}$ brain. (C) Western blot analyses of total protein lysates from whole brain of E16.5 Ikbkap flox/flox and Ikbkap ${ }^{\Delta 20 f l o x}$ embryos. Upper panel shows detection of IKAP with the polyclonal anti-IKAP antibody (AnaSpec), and lower panel shows anti- $\beta$-tubulin staining for loading control. Note that in Ikbkap ${ }^{\Delta 20 / f l o x}$ brain IKAP protein expression is reduced compared to Ikbkap floxflox brain. (D and E) Quantitative analyses of IKAP expression levels in mouse brains of different genotypes. (D) IKAP expression levels were normalized over tubulin levels and are expressed as percentage of WT. (E) IKAP expression levels were

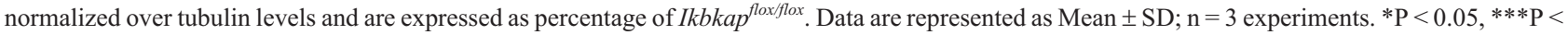
0.001. From Dietrich et al. (2012), by permission of Oxford University Press.

Since FD is caused by severe reduction of full-length IKAP protein, it was reasonable to assume that not only the compound $I k b k a p^{\Delta 20 f f l o x}$ mice but also the Ikbkap floxflox mice would represent a model for FD. As it turns out, both Ikbkap floxflox and Ikbkap ${ }^{\Delta 20 / f l o x}$ mice recapitulate several of FD major phenotypic features, including reduced IKAP expression, intrauterine growth retardation, reduced birth weight, failure to thrive, reduced number of fungiform papillae on the tongue, progressive ataxia, kyphosis, stress-induced seizures, decreased temperature perception and impaired development and maintenance of sensory and sympathetic neurons (Figure 4 and Table1; Dietrich et al.,
2012). Similar to FD patients, these FD mouse models also display reduction of expression of genes and proteins involved in myelination in the CNS (Cheishvili et al., 2014a).

Intriguingly, although both Ikbkaptloxflox and Ikbkap ${ }^{\Delta 20 \text { flox }}$ mouse models recapitulate $\mathrm{FD}$, the severity is strikingly higher in the compound Ikbkap ${ }^{\Delta 20 f l o x}$ model (Table 1). In addition to a milder disease phenotype, Ikbkap ${ }^{f l o x f l o x}$ mice also have a significant increase in longevity. This suggests that a slight increase in IKAP expression is sufficient to greatly ameliorate the symptoms of the disease. Slight differences in IKAP expression (possibly due to differences in splicing efficiency) might therefore 

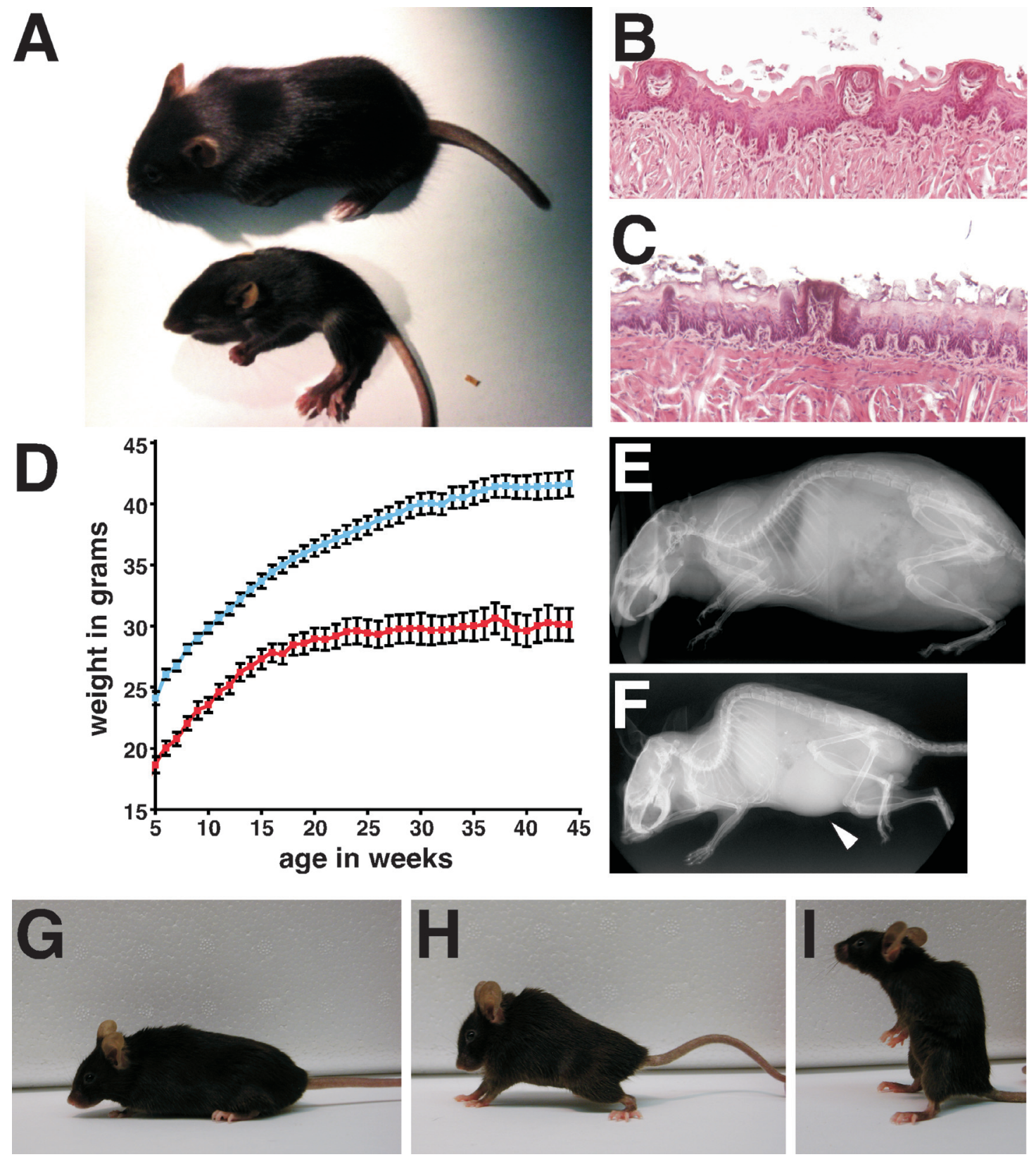

Figure 4 - Postnatal characteristics of Ikbkap ${ }^{\Delta 20 f l o x}$ and Ikbkap floxflox mice. (A) Appearance of Ikbkap ${ }^{\Delta 20 f l o x}$ mice at P18. WT (top) and Ikbkap ${ }^{\Delta 20 f f l o x}$ (bottom) littermates were photographed side by side. Note that the mutant Ikbkap ${ }^{\Delta 20 f l o x}$ mouse is significantly smaller than its WT littermate, exhibits abnormal posture, and puffy feet. (B and C) Representative histological examinations of tongue fungiform papillae. Tongues of P18 WT (B) and Ikbkap ${ }^{\Delta 20 / f l o x}$ (C) littermates were processed for paraffin embedding, and coronal sections of the anterior part of the tongue were stained with H\&E. Note that the three fugiform papillae of the WT littermate appear normal (B), while in the mutant the fungiform papilla shown is degenerating (C). (D) Postnatal growth curves of control (blue, $\mathrm{n}=37$ ) and Ikbkap floxflox $(\mathrm{red}, \mathrm{n}=14)$ male mice. Similar results were found for female mice. Data are represented as Mean $\pm \mathrm{SEM}$. (E and F) MicroCT scans of 11-month-old WT (E) and Ikbkap ${ }^{\Delta 20 / \text { flox }}$ (F) littermate male mice. Note that the mutant is significantly smaller than control and displays a severe curvature of the spine (kyphosis). In this scan, a significant enlargement of the bladder is also observed in the mutant (arrowhead). (G - I) 16-month-old WT (G), and Ikbkap floxflox (H and I) female littermates. Note the spinal curvature of the mutant (H) and the sitting up posture (I) that it assumes frequently. From Dietrich et al. (2012), by permission of Oxford University Press.

also explain the variability in phenotypic expression observed among FD patients. Another important finding through analyses of these models is that intrauterine development of sympathetic ganglia is not extensively compromised even when IKAP levels are as low as $5 \%$ of normal levels, and that degeneration and neuronal cell loss in the sympathetic ganglia occurs mostly postnatally. Significantly, as seen in young FD patients, a portion of the remaining neurons in the sympathetic ganglia of postnatal FD mouse models appear small and vacuolated, an indication of dysfunction and ongoing degeneration (Dietrich et al., 2012). 
Table 1 - Ikbkap ${ }^{\Delta 20 / \text { flox }}$ and Ikbkap ${ }^{\text {flox flox }}$ mouse models reproduce features of FD.

\begin{tabular}{|c|c|c|c|}
\hline & FD patients & Ikbkap ${ }^{\Delta 20 / f l o x}$ & Ikbkap ${ }^{\text {flox/flox }}$ \\
\hline Reduced expression of full-length IKAP protein & $5-20 \%$ of controls in CNS & $5 \%$ of controls in CNS tissues & $10 \%$ of controls in CNS tissues \\
\hline Intrauterine growth retardation & + & + & + \\
\hline Low birth weight & $80 \%$ of controls & $70 \%$ of controls & $85 \%$ of controls \\
\hline Poor suck, uncoordinated swallow at birth & + & + & + \\
\hline Poor weight gain & + & + & + \\
\hline Short stature & + & + & + \\
\hline Reduced life-span & + & + & + \\
\hline Dysautonomic crisis & + & $\mathrm{N} / \mathrm{A}$ & N/A \\
\hline Seizure susceptibility & + & + & + \\
\hline Gastrointestinal dysfunction & + & + & + \\
\hline Absence of overflow emotional tears & + & N/A & N/A \\
\hline Optic neuropathy & + & + & + \\
\hline Tongue: Reduced numbers of fungiform papillae & smooth tongue & $45 \%$ reduction & $30 \%$ reduction \\
\hline Decreased deep tendon reflexes & + & $\mathrm{N} / \mathrm{D}$ & $\mathrm{N} / \mathrm{D}$ \\
\hline Muscle spindle abnormalities & Impaired function & $\mathrm{N} / \mathrm{D}$ & Reduced sensory innervation \\
\hline $\begin{array}{l}\text { Absent axon flare following intradermal histamine } \\
\text { injection }\end{array}$ & + & $\mathrm{N} / \mathrm{D}$ & $\mathrm{N} / \mathrm{D}$ \\
\hline Poor coordination/balance & + & + & + \\
\hline Spinal abnormalities & + & + & + \\
\hline Hydronephrosis & + & + & + \\
\hline Decreased temperature perception & + & + & + \\
\hline Decreased volume of DRGs & + & $45 \%$ of controls at birth & $70 \%$ of controls at birth \\
\hline Decreased neuronal numbers in DRGs in adults & $10-20 \%$ of controls & $\begin{array}{l}75 \% \text { reduction in nociceptive } \\
\text { neurons }\end{array}$ & $\begin{array}{l}20 \% \text { reduction in nociceptive } \\
\text { neurons }\end{array}$ \\
\hline Decreased volume of sympathetic ganglia at birth & $\mathrm{N} / \mathrm{D}$ & $45 \%$ of controls at birth & $70 \%$ of controls at birth \\
\hline Decreased volume of SCGs in adults & $30 \%$ of controls & $\mathrm{N} / \mathrm{D}$ & $30 \%$ of controls \\
\hline Decreased neuronal numbers in SCGs in adults & $10 \%$ of controls & $\mathrm{N} / \mathrm{D}$ & $20 \%$ of controls \\
\hline
\end{tabular}

+: Present ; N/A: Not Applicable ; N/D: Not Determined. From Dietrich et al. (2012), by permission of Oxford University Press.

Taken together, these two findings have major implications for therapeutics, since they suggest that even a slight increase in IKAP expression postnatally might be sufficient to halt the progression of sympathetic neuronal loss, and possibly revert other features as well.

Recently, a phenotypic model of FD in which IKBKAP mRNA splicing and expression can be modulated was generated by introducing the complete human IKBKAP gene (BAC transgene) with the major FD splice mutation $\left(\mathrm{Tg}^{\mathrm{FD}}\right.$; Hims et al., 2007) into the Ikbkap ${ }^{\Delta 20 / f l o x}$ mouse model. The introduction of the human IKBKAP FD transgene attenuated the severe FD phenotype observed in the Ikbkap ${ }^{\Delta 20 f l o x}$ mouse, while still recapitulating FD major features and recreating the same tissue-specific missplicing defect seen in FD patients (Morini et al., 2016). With the availability of mouse models that faithfully recapitulate major features of $\mathrm{FD}$, several questions regarding FD disease process as well as testing of novel therapeutic strategies can now be addressed in vivo.

\section{Conclusions and perspectives}

With the identification of the genetic cause of FD, in vitro and in vivo studies have provided important information related to the normal function of IKAP. In particular, the finding that IKAP plays an essential role in cytoskeleton remodeling and target field innervation provides a plausible explanation for the PNS deficits of the disease. An exciting challenge for the near future is to further elucidate the essential pathways that are disrupted in FD in neuronal and non-neuronal tissues, so that more comprehensive and efficient therapies can be developed and applied to the existing patients. In addition, further understanding of the mechanisms underlying the developmental defects of FD may shed light into other related disorders. For instance, the emerging possible role of IKAP in neurotrophin retrograde transport and signaling - if proven correct - would link the molecular pathways of FD to at least two other HSANs (HSAN IV and HSAN V). With the availability of in vitro and in vivo models for FD, the answers to these questions are now close at hand. 


\section{Acknowledgments}

The authors would like to apologize to all those whose contributions to the field have been inadvertently neglected. The authors were supported by the National Institute of Health [R01 NS061842] and by the Dysautonomia Foundation, Inc.

\section{References}

Abashidze A, Gold V, Anavi Y, Greenspan H and Weil M (2014) Involvment of IKAP in peripheral target innervation and in specific JNK and NGF signaling in developing PNS neurons. PLoS One 9:e113428.

Aguayo AJ, Nair CP and Bray GM (1971) Peripheral nerve abnormalities in the Riley-Day syndrome. Findings in a sural nerve biopsy. Arch Neurol 24:106-116.

Anderson SL, Coli R, Daly IW, Kichula EA, Rork MJ, Volpi SA, Ekstein J and Rubin BY (2001) Familial dysautonomia is caused by mutations of the IKAP gene. Am J Hum Genet 68:753-758.

Anderson SL and Rubin BY (2005) Tocotrienols reverse IKAP and monoamine oxidase deficiencies in familial dysautonomia. Biochem Biophys Res Commun 336:150-156.

Aring CD and Engel GD (1945) Hypothalamic attacks with thalamic lesions: II anatomic considerations. Arch Neurol Psychiat 54:44.

Axelrod FB (2004) Familial dysautonomia. Muscle Nerve 29:352-363.

Axelrod FB (2006) A world without pain or tears. Clin Auton Res 16:90-97.

Axelrod FB and Dancis J (1973) Intrauterine growth retardation in familial dysautonomia. Am J Dis Child 125:379-380.

Axelrod FB and Pearson J (1984) Congenital sensory neuropathies. Diagnostic distinction from familial dysautonomia. Am J Dis Child 138:947-954.

Axelrod FB, Iyer K, Fish I, Pearson J, Sein ME and Spielholz N (1981) Progressive sensory loss in familial dysautonomia. Pediatrics 67:517-522.

Axelrod FB, Goldberg JD, Ye XY and Maayan C (2002) Survival in familial dysautonomia: Impact of early intervention. J Pediatr 141:518-523.

Axelrod FB, Hilz MJ, Berlin D, Yau PL, Javier D, Sweat V, Bruehl H and Convit A (2010) Neuroimaging supports central pathology in familial dysautonomia. J Neurol 257:198206.

Bar-On E, Floman Y, Sagiv S, Katz K, Pollak RD and Maayan C (2000) Orthopaedic manifestations of familial dysautonomia. A review of one hundred and thirty six patients. J Bone Joint Surg Am 82-A:1563-1570.

Blumenfeld A, Slaugenhaupt SA, Liebert CB, Temper V, Maayan C, Gill S, Lucente DE, Idelson M, MacCormack K, Monahan MA, et al. (1999) Precise mapping and haplotype analysis of the familial dysautonomia gene on human chromoseome 9q31. Am J Hum Genet 64:1110-1118.

Bochner R, Ziv Y, Zeevi D, Donyo M, Abraham L, Ashery-Padan $R$ and Ast $G$ (2013) Phosphatidylserine increases IKBKAP levels in a humanized knock-in IKBKAP mouse model. Hum Mol Genet 22:2785-2794.

Boone N, Loriod B, Bergon A, Sbai O, Formisano-Tréziny C, Gabert J, Khrestchatisky M, Nguyen C, Féron F, Axelrod
FB, et al. (2010) Olfactory stem cells, a new cellular model for studying molecular mechanisms underlyng familial dysautonomia. PLoS One 5:e15590.

Brown WJ, Beauchemin JA and Linde LM (1964) A neuropathological study of familial dysautonomia (Riley-Day syndrome) in siblings. J Neurol Neurosurg Psychiatry 27:131-139.

Capsoni S (2014) From genes to pain: Nerve growth factor and hereditary sensory and autonomic neuropathy type V. Eur J Neurosci 39:392-400.

Carroll MS, Kenny AS, Patwari PP, Ramirez JM and WeeseMayer DE (2012) Respiratory and cardiovascular indicators of autonomic nervous system dysregulation in familial dysautonomia. Pediatr Pulmonol 47:682-691.

Cheishvili D, Maayan C, Smith Y, Ast G and Razin A (2007) IKAP/hELP1 deficiency in the cerebrum of familial dysautonomia patiemnts results in down regulation of genes involved in oligodendrocyte differentiation and in myelination. Hum Mol Genet 16:2097-2104.

Cheishvili D, Maayan C, Cohen-Kupiec R, Lefler S, Weil M, Ast $\mathrm{G}$ and Razin A (2011) IKAP/Elp1 involvment in cytoskeleton regulation and implication for familial dysautonomia. Hum Mol Genet 20:1585-1594.

Cheishvili D, Dietrich P, Maayan C, Even A, Weil M, Dragatsis I and Razin A (2014a) IKAP deficiency in an FD mouse model and in oligodendrocyte precursor cells results in downregulation of genes involved in oligodendrocyte differentiation and myelin formation. PLoS One 9:e94612.

Cheishvili D, Laiba E, Rekhtman D, Claman A, Razin A and Maayan C (2014b) Dynamic changes in IKBKAP mRNA levels during crisis of familial dysautonomia. Auton Neurosci 180:50-65.

Chen YT, Hims MM, Shetty RS, Mull J, Liu L, Leyne M and Slaugenhaupt SA (2009) Loss of mouse Ikbkap, a subunit of elongator, leads to transcriptional deficits and embryonic lethality that can be rescued by human IKBKAP. Mol Cell Biol 29:736-744.

Close P, Hawkes N, Cornez I, Creppe C, Lambert CA, Rogister B, Siebenlist U, Merville MP, Slaugenhaupt SA, Bours V, et al. (2006) Transcription impairment and cell migration defects in elongator-depleted cells: Implication for familial dysautonomia. Mol Cell 22:521-531.

Cohen P and Solomon NH (1955) Familial dysautonomia: Case report with autopsy. J Pediatr 46:663-670.

Cohen L, Henzel WJ and Baeuerle PA (1998) IKAP is a scaffold protein of the IkappaB complex. Nature 395:292-296.

Cohen-Kupiec R, Pasmanik-Chor M, Oron-Karni V and Weil M (2011) Effects of IKAP/hELP1 deficiency on gene expression in differentiating neuroblastoma cells: Implications for familial dysautonomia. PLoS One 6:e19147.

Coli R, Anderson SL, Volpi SA and Rubin BY (2001) Genomic organization and chromosomal localization of the mouse IKBKAp gene. Gene 279:81-89.

Couzin-Frankel J (2010) Chasing a disease to the vanishing point. Science 328:298-300.

Creppe C, Malinouskaya L, Volvert ML, Gillard M, Close P, Malaise $\mathrm{O}$, Laguesse S, Cornez I, Rahmouni S, Ormenese S, et al. (2009) Elongator controls the migration and differentiation of cortical neurons through acetylation of alpha-tubulin. Cell 136:551-564. 
Cuajungco MP, Leyne M, Mull J, Gill SP, Gusella JF and Slaugenhaupt SA (2001) Cloning, characterization and genomic structure of the mouse Ikbkap gene. DNA Cell Biol 20:579586.

Cuajungco MP, Leyne M, Mull J, Gill SP, Lu W, Zagzag D, Axelrod FB, Maayan C, Gusella JF and Slaugenhaupt SA (2003) Tissue-specific reduction in splicing efficiency of IKBKAP due to the major mutation associated with familial dysautonomia. Am J Hum Genet 72:749-758.

Davies AM (2000) Neurotrophins: More to NGF than survival. Curr Biol 10:R374-R376.

Davies AM, Bandtlow C, Heumann R, Korsching S, Rohrer H and Thoenen H (1987) Timing and site of nerve growth factor synthesis in the developing skin in relation to innervation and expression of the receptor. Nature 326:353-358.

Dietrich P, Alli S, Shanmugasundaram R and Dragatsis I (2012) IKAP expression levels modulate disease severity in a mouse model of familial dysautonomia. Hum Mol Genet 21:5078-5090.

Dietrich P, Yue J, Shuyu E and Dragatsis I (2011) Deletion of exon 20 of the Familial Dysautonomia gene Ikbkap in mice causes developmental delay, cardiovascular defects, and early embryonic lethality. PLoS One 6:e27015.

Dong J, Edelmann L, Bajwa AM, Kornreich R and Desnick RJ (2002) Familial dysautonomia: Detection of the IKBKAP IVS20 $(+6 \mathrm{~T}>\mathrm{C})$ and R696P mutations and frequencies among Ashkenazi Jews. Am J Med Genet 110:253-257.

Dyck PJ (1993) Neuronal atrophy and degeneration predominantly affecting peripheral sensory and autonomic neurons. In: Dyck PJ, Thomas PK, Griffin JW, Low PA and Poduslo JF (eds) Peripheral Neuropathy. 3rd edition. WB Saunders Co, Philadelphia, pp 1065-1093.

Elkabes S, Dreyfus CF, Schaar DG and Black IB (1994) Embryonic sensory development: Local expression of neyrotrophin-3 and target expression of nerve growth factor. J Comp Neurol 341:204-213.

Fogelson MH, Rorke LB and Kaye R (1967) Spinal cord changes in familial dysautonomia. Arch Neurol 17:103-108.

Freytag E and Lindenberg R (1967) Neuropathological findings in patients of a hospital for the mentally deficient. A survey of 359 cases. Johns Hopkins Med J 121:379-392.

George L, Chaverra M, Wolfe L, Thorne J, Close-Davis M, Eibs A, Riojas V, Grindeland A, Orr M, Carlson GA, et al. (2013) Familial dysautonomia model reveals Ikbkap deletion causes apoptosis of Pax3+ progenitors and peripheral neurons. Proc Natl Acad Sci U S A 110:18698-18703.

Glatt S and Müller CW (2013) Structural insights into Elongator function. Curr Opin Struct Biol 23:235-242.

Gold-von Simson G and Axelrod FB (2006) Familial dysautonomia: Update and recent advances. Curr Probl Pediatr Adolesc Health Care 36:218-237.

Goldberg MF, Payne JW and Brunt PW (1968) Ophthalmologic studies of familial dysautonomia. The Riley-Day syndrome. Arch Ophthalmol 80:732-743.

Goldstein DS, Eldadah B, Sharabi Y and Axelrod FB (2008) Cardiac sympathetic hypo-innervation in familial dysautonomia. Clin Auton Res18:115-119.

Groom M, Kay MD and Corrent GF (1997) Optic neuropathy in familial dysautonomia. J Neuroophthalmol 17:101-102.
Gutiérrez JV, Norcliffe-Kaufmann L and Kaufmann H (2015) Brainstem reflexes in patients with familial dysautonomia. Clin Neurophysiol 126:626-633.

Guzzetta F, Tortorella G, Cardia E and Ferrière G (1986) Familial dysautonomia in a non-Jewish girl, with histological evidence of progression in the sural nerve. Dev Med Child Neurol 28:62-68.

Hawkes NA, Otero G, Winkler GS, Marshall N, Dahmus ME, Krappmann D, Scheidereit C, Thomas CL, Schiavo G, Erdjument-Bromage H, et al. (2002) Purification and characterization of the human elongator complex. J Biol Chem 277:3047-3052.

Hilz MJ, Axelrod FB, Bickel A, Stemper B, Brys M, Wendelschafer-Crabb G and Kennedy WR (2004) Assessing function and pathology in familial dysautonomia: Assessment of temperature perception, sweating and cutaneous innervation. Brain 127:2090-2098.

Hilz MJ, Stemper B, Sauer P, Haertl U, Singer W and Axelrod FB (1999) Cold face test demonstrates parasympathetic cardiac dysfunction in familial dysautonomia. Am J Physiol 276:R1833-R1839.

Hims MM, Shetty RS, Pickel J, Mull J, Leyne M, Liu L, Gusella JF and Slaugenhaupt SA (2007) A humanized IKBKAP transgenic mouse models a tissue-specific human splicing defect. Genomics 90:389-396.

Holmberg C, Katz S, Lerdrup M, Herdegen T, Jäättelä M, Aronheim A and Kallunki T (2002) A novel specific role for I kappa B kinase complex-associated protein in cytosolic stress signaling. J Biol Chem 277:31918-31928.

Hunnicutt BJ, Chaverra M, George L and Lefcort F (2012) IKAP/ELP1 is required in vivo for neurogenesis and neuronal survival, but not for neural crest migration. PLoS One 7:e32050.

Ibrahim EC, Hims MM, Shomron N, Burge CB, Slaugenhaupt SA and Reed R (2007) Weak definition of IKPKAP exon 20 leads to aberrant splicing in familial dysautonomia. Hum Mutat 28:41-53.

Indo Y (2014) Neurobiology of pain, interoception and emotional response: Lessons from nerve growth factor-dependent neurons. Eur J Neurosci 39:375-391.

Jackson MZ, Gruner KA, Qin C and Tourtellotte WG (2014) A neuron autonomous role for the familial dysautonomia gene ELP1 in sympathetic and sensory target tissue innervation. Development 141:2452-2461.

Johansen LD, Naumanen T, Knudsen A, Westerlund N, Gromova I, Junttila M, Nielsen C, Bøttzauw T, Tolkovsky A, Westermarck J, et al. (2008) IKAP localizes to membrane ruffles with filamin A and regulates actin cytoskeleton organization and cell migration. J Cell Sci 121:854-864.

Kapitein LC and Hoogenraad CC (2015) Building the neuronal microtubule cytoskeleton. Neuron 87:492-506.

Kaplan L, Margulies JY, Kadari A, Floman Y and Robin GC (1997) Aspects of spinal deformity in familial dysautonomia (Riley-Day syndrome). Eur Spine J 6:33-38.

Karlsborn T, Tükenmez H, Mahmud AK, Xu F, Xu H and Byström AS (2014) Elongator, a conserved complex required for wobble uridine modification in eukaryotes. RNA Biol 11:1519-1528.

Krappmann D, Hatada EN, Tegethoff S, Li J, Klippel A, Giese K, Baeuerle PA and Scheidereit C (2000) The IkappaB kinase (IKK) complex is tripartite and contains IKK gamma but not 
IKAP as a regular component. J Biol Chem 275:2977929787.

Laguesse S, Creppe C, Nedialkova DD, Prévot PP, Borgs L, Huysseune S, Franco B, Duysens G, Krusy N, Lee G, et al. (2015) A dynamic unfolded protein response contributes to the control of cortical neurogenesis. Dev Cell 35:553-567.

Lahat E, Aladjem M, Mor A, Azizi E and Arlazarof A (1992) Brainstem auditory evoked potentials in familial dysaiutonomia. Dev Med Child Neurol 34:690-693.

Laplaza FJ, Turajane T, Axelrod FB and Burke SW (2001) Nonspinal orthopaedic problems in familial dysautonomia (Riley-Day syndrome). J Pediatr Orthop 21:229-232.

Lee G, Papapetrou EP, Kim H, Chambers SM, Tomishima MJ, Fasano CA, Ganat YM, Menon J, Shimizu F, Viale A, et al. (2009) Modelling pathogenesis and treatment of familial dysautonomia using patient-dpecific iPSCs. Nature 461:402-406.

Lehavi O, Aizenstein O, Bercovich D, Pavzner D, Shomrat R, Orr-Urtreger A and Yaron Y (2003) Screening for familial dysautonomia in Israel: Evidence for higher carrier rate among Polish Ashkenazi Jews. Genet Test 7:139-142.

Lefler S, Cohen MA, Kantor G, Cheishvili D, Even A, Birger A, Turetsky T, Gil Y, Even-Ram S, Aizenman E, et al. (2015) Familial dysautonomia (FD) human embryonic stem cell derived PNS neurons reveal that synaptic vesicular and neuronal transport genes are directly or indirectly affected by IKBKAP downregulation. PLoS One 10:e138807.

Leyne M, Mull J, Gill SP, Cuajungco MP, Oddoux C, Blumenfeld A, Maayan C, Gusella JF, Axelrod FB and Slaugenhaupt SA (2003) Identification of the first non-Jewish mutation in Familial Dysautonomia. Am J Med Genet A 118A:305-308.

Li Q, Fazly AM, Zhou H, Huang S, Zhang Z and Stillman B (2009) The elongator complex interacts with PCNA and modulates transcriptional silencing and sensitivity to DNA damage agents. PLoS Genet 5:e1000684.

Lin FJ, Shen L, Jang CW, Falnes PØ and Zhang Y (2013) Ikbkap/Elp1 deficiency causes male infertility by disrupting meiotic progression. PLoS Genet 9:e1003516.

Maayan C, Bar-On E, Foldes AJ, Gesundheit B and Pollak RD (2002) Bone mineral density and metabolism in familial dysautonomia. Osteoporos Int 13:429-433.

Macefield VG, Norcliffe-Kaufmann LJ, Axelrod FB and Kaufmann H (2013) Relationship between proprioception at the knee joint and gait ataxia in HSAN III. Mov Disord 28:823-827.

Macefield VG, Norcliffe-Kaufmann L, Gutiérrez J, Axelrod FB and Kaufmann H (2011) Can loss of muscle spindle afferents explain the ataxic gait in Riley-Day syndrome? Brain 134:3198-3208.

Margulies SI, Brunt PW, Donner MW and Silbiger ML (1968) Familial dysautonomia: A cineradiographic study of the swallowing mechanism. Radiology 90:107-112.

Mass E, Brin I, Belostoky L, Maayan C and Gadoth N (1998) A cephalometric evaluation of craniofacial morphology in familial dysautonomia. Cleft Palate Craniofac J 35:120-126.

Mendoza-Santiesteban CE, Hedges III TR, Norcliffe-Kaufmann L, Axelrod F and Kaufmann H (2014) Selective retinal ganglion cell loss in familial dysautonomia. J Neurol 261:702709 .

Mendoza-Santiesteban CE, Hedges TR 3rd, Norcliffe-Kaufmann L, Warren F, Reddy S, Axelrod FB and Kaufmann H (2012)
Clinical neuro-ophthalmic findings in familial dysautonomia. J Neuroophthalmol 32:23-26.

Mezey E, Parmalee A, Szalayova I, Gill SP, Cuajungco MP, Leyne M, Slaugenhaupt SA and Brownstein MJ (2003) Of splice and men: What does the distribution of IKAP mRNA in the rat tell us about the pathogenesis of familial dysautonomia? Brain Res 983:209-214.

Morini E, Dietrich P, Salani M, Downs HM, Wojtkiewicz GR, Alli S, Brenner A, Nilbratt M, LeClair JW, Oaklander AL, et al. (2016) Sensory and autonomic deficits in a new humanized model of familial dysautonomia. Hum Mol Genet 25:1116-1128.

Nguyen L, Humbert S, Saudou F and Chariot A (2010) Elongator - An emerging role in neurological diseases. Trends Mol Med 16:1-6.

Norcliffe-Kaufmann L, Axelrod F and Kaufmann H (2010) Afferent baroreflex failure in familial dysutonomia. Neurology 75:1904-1911.

Norcliffe-Kaufmann L, Axelrod FB and Kaufmann H (2013) Developmental abnormalities, blood pressure variability and renal disease in Riley Day syndrome. J Hum Hypertens 27:51-55.

Okada Y, Yamagata K, Hong K, Wakayama T and Zhang Y (2010) A role for the elongator complex in zygotic paternal genome demethylation. Nature 463:554-558.

Otero G, Fellows J, Li Y, de Bizemont T, Dirac AM, Gustafsson CM, Erdjument-Bromage H, Tempst P and Svejstrup JQ (1999) Elongator, a multisubunit component of a novel polymarease II holoenzyme for transcriptional elongation. Mol Cell 3:109-118.

Pearson J, Brandeis L and Goldstein M (1979) Tyrosine hydroxylase immunoreactivity in familial dysautonomia. Science 206:71-72.

Pearson J and Pytel B (1978) Quantitative studies of ciliary and sphenopalatine ganglia in familial dysautonomia. J Neurol Sci 39:123-130.

Pearson J, Finegold MJ and Budzilovich G (1970) The taste and tongue in familial dysautonomia. Pediatrics 45:739-745.

Pearson J, Dancis J, Axelrod F and Grover N (1975) The sural nerve in familial dysautonomia. J Neuropathol Exp Neurol 34:413-424

Pearson J, Pytel BA, Grover-Johnson N, Axelrod F and Dancis J (1978) Quantitative studies of dorsakl root ganglia and neuropathologic observations on spinal cords in familial dysautpnomia. J Neurol Sci 35:77-92.

Riley CM, Day RL, Greely D and Langford WS (1949) Central autonomic dysfunction with defective lacrimation. Pediatrics 3:468-477.

Riley CM and Moore RH (1966) Familial dysautonomia differentiated from related disorders. Case reports and discussions of current concepts. Pediatrics 37:435-446.

Rizzo 3rd JF, Lessell S and Liebman SD (1986) Optic atrophy in familial dysautonomia. Am J Ophthalmol 102:463-467.

Rotthier A, Baets J, Timmerman V and Janssens K (2012) Mechanisms of disease in hereditary sensory and autonomic neuropathies. Nat Rev Neurol 8:73-85.

Schwartz JP and Breakefield XO (1980) Altered nerve growth factor in fibroblasts from patients with familial dysautonomia. Proc Natl Acad Sci U S A 77:1154-1158.

Shelton DL and Reichardt LF (1984) Expression of the beta-nerve growth factor gene correlates with the density of sympa- 
thetic innervation in effector organs. Proc Natl Acad Sci U S A 81:7951-7955.

Shetty RS, Gallagher CS, Chen YT, Hims MM, Mull J, Leyne M, Pickel J, Kwok D and Slaugenhaupt SA (2011) Specific correction of a splice defect in brain by nutritional supplementation. Hum Mol Genet 20:4093-4101.

Siggers DC, Rogers JG, Boyer SH, Margolet L, Dorkin H, Banerjee SP and Shooter EM (1976) Increased nerve-growthfactor beta-chain cross-reacting material in familial dysautonomia. N Engl J Med 295:629-634.

Silveira AL, Binkowski RT, Rich BF, Benetti MB and Almeida AM (2012) Hereditary sensory and autonomic neuropathy type 3 in non-Jewish child. Arq Neuropsiquiatr 70:900-901.

Slaugenhaupt SA, Blumenfeld A, Gill SP, Leyne M, Mull J, Cuajungco MP, Liebert CB, Chadwick B, Idelson M, Reznik L, et al. (2001) Tissue-specific expression of a splicing mutation in the IKBKAP gene causes familial dysautonomia. Am J Hum Genet 68:598-605.

Smith AA, Taylor T and Wortis SB (1963) Abnormal catechol amine metabolism in familial dysautonomia. N Engl J Med 268:705-707.

Solitare GB (1991) Familial dysautonomia. In: de Jong JMBV (ed) Handbook of Clinical Neurology. Elsevier Science Publishers, Amsterdam, pp 23-38.

Solitare GB and Cohen GS (1965) Peripheral autonomix nervous system lesions in congenital or familial dysautonomia. Riley-Day syndrome. Neurology 15:321-327.

Stemper B, Bernardi L, Axelrod FB, Welsch G, Passino C and Hilz MJ (2004) Sympathetic and parasympathetic baroreflex dysfunction in familial dysautonomia. Neurology 63:1427-1431.
Steventon B, Mayor R and Streit A (2014) Neural crest and placode interaction during the development of the cranial sensory system. Dev Biol 389:28-38.

Téllez MJ (2015) Evidence of brainstem dysfunction in patients with familial dysautonomia and carriers of the IKBKAp mutation. Clin Neurophysiol 127:1748-1749.

Tokita N, Sekhar HK, Sachs M and Daly JF (1978) Familial Dysautonomia (Riley-Day syndrome). Temporal bone findings and otolaryngological manifestations. Ann Otol Rhinol Laryngol Suppl 87:1-12.

Welton W, Clayson D, Axelrod FB and Levine DB (1979) Intellectual development and familial dysautonomia. Pediatrics 63:708-712.

Wolff A, Harell D, Gadoth N and Mass E (2002) Submandibular and sublingual salivary gland function in familial dysautonomia. Oral Surg Oral Med Oral Pathol Oral Radiol Endod 94:315-319.

Wrathall JR (1986) Reduced neuronotrophic activity of fibroblasts from individuals with dysautonomia in cultures of mouse sensory ganglion cells. Brain Res 364:23-29.

Xu H, Lin Z, Li F, Diao W, Dong C, Zhou H, Xie X, Wang Z, Shen $Y$ and Long J (2015) Dimerization of elongator protein 1 is essential for Elongator complex assembly. Proc Natl Acad Sci U S A 112:10697-106702.

Yatsu F and Zussman W (1964) Familial dysautonomia (RileyDay symdrome). Case report with postmortem findings of a patient at age 31. Arch Neurol 10:459-463.

Associate Editor: Carlos F. M. Menck

License information: This is an open-access article distributed under the terms of the Creative Commons Attribution License (type CC-BY), which permits unrestricted use, distribution and reproduction in any medium, provided the original article is properly cited. 